\title{
Quality health care for cancer survivors: A survivor's perspective
}

\author{
Michael Feuerstein
}

Received: 16 January 2009 / Accepted: 17 January 2009/ Published online: 13 March 2009

(C) Springer Science + Business Media, LLC 2009

\section{Health as the focus}

Studies confirm the limits of health care for survivors of many types of cancer. A recent population health study of quality care indicators using the National Cancer Data Base Infrastructure found that a little over half of the patients receiving radical prostatectomy or external beam radiation therapy for early stage prostate cancer had a follow up visit after treatment [1]. There is also evidence that preventative health care falls by the wayside, as subsequent visits to the doctor tend to focus primarily on the tumor and potential recurrence [2]. What about efforts to assist in maintaining overall health, well-being, and function? Don't these outcomes reflect the World Health Organization's definition of health; "a state of complete physical, mental, and social well-being and not merely the absence of disease or infirmity?" [3] While not fully achievable for all, maintaining overall health and well-being seems a worthy goal to aspire to. Currently, achieving any of these goals is mainly left to the survivor [4]. It is daunting, even for someone who knows the vagaries of the health care system. Many elements need to be continuously tracked (e.g., general health, residual symptoms, well-being, overall function, and health behavior) and integrated into the cancer survivor's health care even years after being cancer free [4]. This journal was launched to help facilitate such efforts and is committed to "fast tracking" manuscripts that systematically study these matters.

M. Feuerstein $(\square)$

Departments of Medical and Clinical Psychology

and Preventive Medicine and Biometrics Uniformed Services,

University of the Health Sciences,

4301 Jones Bridge Rd.,

Bethesda, MD 20814-4799, USA

e-mail: jcancersurvivorship@gmail.com
Cancer survivors - those young and old, those with comorbidities, those of minority groups, those from various educational and economic backgrounds and with private or government supported health care-all experience the challenges of optimizing health over time. Fractionated health care continues to be the norm. However, innovative training efforts to help others establish quality programs of care for cancer survivorship have been designed and represent one promising way to expand quality services [5]. This journal is honored to publish the first paper on the LIVESTRONG Survivorship Center of Excellence Network whose mission it is to develop, provide, evaluate, and promulgate innovative models of health care. Through their efforts we will learn much about the elements and delivery of quality care for cancer survivors.

In addition to these Centers of Excellence and the many other important initiatives around the world that will yield improvements in the future, we also need to find more immediate solutions. What about mobilizing the thousands of licensed health care providers currently working in communities across the world to positively impact the health of our current cancer survivor population? These providers represent a critical resource for improving health, well-being, and function in this ever-increasing population. Many health care providers are just beginning to define their potential role in improving outcomes in cancer survivors. Studies that determine the feasibility, costs, and outcomes of such grassroots clinical efforts would be most welcome in the Journal of Cancer Survivorship: Research and Practice. Comprehensive integrated care will continue to evolve in academic medical centers, community hospitals, and other settings. However, it is time we increase efforts even further and widen the network of providers in order to adequately address the patchwork of problems that cancer survivors face.

Costly technology is generally not required in cancer survivorship care beyond cancer surveillance and of course, 
recurrence. Many licensed health care providers (e.g., local physicians, nurses, nutritionists, exercise physiologists, physical therapists, occupational therapists, social workers, psychologists, Complimentary and Alternative Medicine practitioners) can offer necessary services in their current practices and bill for or record these services as part of their current clinical activity. There have been some efforts to train family practitioners in cancer survivor care. This training approach may serve as a useful model for other groups of providers [6].

These days, licensed health care providers of all types typically employ evidence based care in their respective fields. While we must await specific evidence to identify the most effective approaches specific to cancer survivor health care and self-management, this has never been a reason for not acting at all! The delivery of comprehensive, integrative health care for other chronic illnesses may offer some guidance [7]. Placed within the broader context of modern health care both in the U.S. and around the world, constrained resources and human capital make it ever more important that we generate options that represent real change and evaluate them appropriately for their efficacy and cost benefit. We then need the wherewithal to implement them. We need many more researchers and practitioners generating all sorts of creative options. You come up with them and evaluate them, and we will publish them.

\section{The Cancer Survivorship Care Plan: A viable first step}

Let's consider the Cancer Survivorship Care Plan (CSCP), an innovative tool that provides a clinical process to assist providers and survivors integrate multiple sources of clinical information. The result of such a plan is to facilitate the identification and prioritization of current and long-term efforts to improve and maintain optimal health, health care, well-being, and function [8]. The CSCP considers past and current personal and family health status, long-term and projected late effects, and incorporates the current clinical picture with a proposed plan for long term care and necessary health behavior change [10]. The CSCP organizes and combines past, present, and future information regarding one's health, well-being, and function within the context of cancer. This face valid improvement in quality care requires research to demonstrate its effectiveness [9] but let me tell you a little about my experience with the CSCP.

\section{Case: MF}

My case will serve as an example of just how useful this process can be. I have been very fortunate to consult highly knowledgeable and skilled providers in several specialties related to my initial care and post-treatment problems over the past six and a half years. I was diagnosed with a malignant brain tumor (anaplastic astrocytoma grade III in my right cerebellum spreading into my pons) at age 52 . I received a resection, $60 \mathrm{~Gy}$ of radiation, and 12 months of chemotherapy. During and following this, I continued to experience fatigue, dysphoria, cognitive limitations, weight gain, physical inactivity, and episodic visual blurriness despite many attempts to manage these new problems. My blood work was showing a progressive movement toward a diagnosis of a metabolic syndrome. My family history of diabetes, hypertension, and stroke put me at further risk. Despite knowing all about the importance of health behavior change and even how to achieve it, I wasn't doing what I needed to do. Ironically as someone who has spent his professional career working with multidisciplinary teams to comprehensively address chronic health problems, I was caught up in searching for evidence-based explanations and solutions to my symptoms from primarily a biomedical perspective. Although the biomedical approach helped, it could not fully address my persistent symptom burden.

In 2006, after reading about the Cancer Survivorship Care Plan in the IOM report [10] it sounded like it was "just what I needed." Although I did benefit greatly from the quality care I received from individual specialists and my primary care physician, I felt that something was missing. I continued to experience problems that impacted my life. Based on my professional background I thought there was a good chance that I would learn something new from a multi-specialty group that was knowledgeable about the problems and late effects in cancer survivors. I began to think, and many had told me, that maybe I should just accept how I was feeling as my "new normal." Although I was productive, I felt out of sorts much of the time and still hoped that something could help. Also, regardless of what I read in the literature and in my MRI reports, I didn't have a good idea of the late effects of the tumor or treatment exposures. I thought that despite the lack of available definitive information and services that targeted brain tumor survivors at the time, there must be someone out there that could provide me with a better understanding of what was happening to me and what I needed to do to improve my situation. I searched for a group that offered this "comprehensive review and plan." I made calls to different health care facilities and was informed that there was nothing like what I described. I live in the Washington, DC greater metropolitan area. Even with many of the world's top rated health care resources and my ability to access them, I was unable to find this type of service.

I was fortunate to have met Dr. Patricia Ganz from UCLA a few years ago. She was instrumental in developing the CSCP $[10,11]$ and a pioneer in the health care needs of cancer survivors. She generously offered to provide me with an evaluation and Cancer Survivor Care Plan. When I arrived, I felt that for the first time since my primary treatment, I was being seen as a "survivor" of a malignant brain tumor. My problems, while taken seriously all along, were now placed 
in the context of a cancer survivor. The team at UCLA placed greater focus on my current and long-term health as someone who had very invasive treatment for brain cancer and wants to be as healthy as possible. While an oncologist coordinated the evaluation, I was also seen by an endocrinologist, nurse specialist, and social worker, and was given a comprehensive evaluation and realistic intervention options. I felt that I was on the right track. It was a relief.

This evaluation provided me with a better sense of my current general medical condition, potential late effects, well-being, and the need to reestablish health behaviors as someone who went through treatment for brain cancer. I received a new medication that turned out to be more effective in helping my mood, fatigue, and weight loss efforts, a better perspective on how to manage my hearing loss, and a renewed sense for the need to and guidelines for changing key health behaviors. A vitamin D deficiency was also identified and a plan to mitigate this was initiated. What cancer survivor wouldn't want something like this?

Action steps you can take

Consider what you, your institutions, or practices are doing to provide such comprehensive and integrative care for cancer survivors who may need something like this service. While we all want to implement the best evidence-based approaches available, does this mean we sit by the sidelines until we have the evidence? Don't many of these changes really represent the provision of quality health care in the 21 st century? While the elements of good practice have been promulgated since the early days of Hippocrates [12], they have been modernized given current societal demands, operationalized within the context of modern health care, and do serve as useful guidelines for generic quality health care [13]. Pull the case together, listen, develop sound treatment plans based upon the best available evidence, and follow up. A review of various approaches to achieve quality care for adult cancer survivors has recently been published [14]. Also, much can be learned from cancer survivor health care efforts in childhood cancers because of the experience in providing long term quality care [15]. Even when offering quality health care, we know that some patients just do not follow through. This may be on the increase in cases where patients share the cost or pay for all of the care. Therefore it is also important to remember that economics needs to enter into any effort to tweak existing health care in all systems across the world. The clinical, social, and economic analyses of reform efforts is also a major interest of this journal so we may all learn how to make necessary change happen.

\section{Better than new}

The tireless quality efforts of surgeons, oncologists, radiologists, and nurses to manage cancer are the very reason we are surviving. But what is the purpose of saving lives in a vacuum of quality follow up care? Also, it is very important for all of us to realize that many cancer survivors don't want to simply accept a "new normal." Instead they want their "old normal" back or to return as close to "normal" as possible. Some may even want to go beyond their "old normal." While innovation in the quality of health care is by definition a continuous process and reform takes time, there is an urgent need to "step up" efforts so the current cohort of cancer survivors can benefit.

\section{References}

1. Spencer BA, Miller DC, Litwin MS, Ritchey JD, Stewart AK, Dunn $\mathrm{RL}$, et al. Variations in quality of care for men with early-stage prostate cancer. J Clin Oncol. 2008;26:3735-42. doi:10.1200/ JCO.2007.13.2555.

2. Earle CC, Burstein HJ, Winer EP, Weeks JC. Quality of non-breast cancer health maintenance among elderly breast cancer survivors. J Clin Oncol. 2003;21:1447-51. doi:10.1200/JCO.2003.03.060.

3. World Health Organisation. Ethics and health, and quality in health care-report by the director general. Geneva: WHO; 1996.

4. Feuerstein M, Findley P. The Cancer Survivors' Guide: The Essential Handbook to Life After Cancer. New York, NY: Marlow \& Company; 2006.

5. Grant M, Economou D, Ferrell B, Bhatia S. Preparing professional staff to care for cancer survivors. Journal of Cancer Survivorship. 2007;1:98-106. doi:10.1007/s11764-007-0008-z.

6. Blaauwbroek R, Zwart N, Bouma M, Meyboom-de Jong B, Kamps WA, Postma A. The willingness of general practitioners to be involved in the follow-up of adult survivors of childhood cancer. Journal of Cancer Survivorship. 2007;1:292-7. doi:10.1007/s11764-007-0032-z.

7. Bodenheimer T, Wagner EH, Grumbach K. Improving primary care for patients with chronic illness. JAMA. 2002;288:1775-9. doi:10.1001/jama.288.14.1775.

8. Ganz PA, Hahn EE. Implementing a survivorship care plan for patients with breast cancer. J Clin Oncol. 2008;26:759-67. doi:10.1200/JCO.2007.14.2851.

9. Earle CC. Long term care planning for cancer survivors: A health services research agenda. Journal of Cancer Survivorship. 2007;1:64-74. doi:10.1007/s11764-006-0003-9.

10. Hewitt M, Greenfield S, Stovall E. From Cancer Patient to Cancer Survivor: Lost in Transition. The National Academies: Washington DC ; 2006.

11. Ganz PA, Casillas J, Hahn EE. Ensuring quality care for cancer survivors: implementing the survivorship care plan. Sem Oncol Nurs. 2008;24:208-17. doi:10.1016/j.soncn.2008.05.009.

12. Bulger RJ, Barbato AL. On the Hippocratic sources of Western medical practice. Hastings Cent Rep. 2000;30:S4-S7. doi: $10.2307 / 3527655$

13. Committee on Quality of Health Care in America. Crossing the Quality Chasm: A New Health System for the 21st Century. Washington, DC: The National Academies; 2001.

14. Oeffinger KC, McCabe MS. Models for delivering survivorship care. J Clin Oncol. 2006;24:5117-24. doi:10.1200/ JCO.2006.07.0474.

15. Oeffinger KC, Robison LL. Childhood cancer survivors, late effects, and a new model for understanding survivorship. JAMA. 2007;297:2762-4. doi:10.1001/jama.297.24.2762. 